\title{
Operative Chest Wall Fixation with Osteosynthesis Plates
}

\author{
Christine Engel, MD, James C. Krieg, MD, Steven M. Madey, MD, William B. Long, MD, and \\ Michael Bottlang, PhD
}

J Trauma. 2005;58:181-186.

D lunt chest wall trauma is a major cause of morbidity and

D mortality, especially in the presence of a flail chest where paradoxical inward movement of the flail segment in inspiration is found. ${ }^{1-3}$

Patients with a flail chest require aggressive pain control, pulmonary toilet, and often intubation and mechanical ventilation to establish an internal pneumatic stabilization of the flail segment. This may result in a prolonged ICU stay and pulmonary complications including pneumonia, septicemia and barotrauma. ${ }^{3-9}$ The high mortality rate of up to $10-36 \%^{3,10-12}$ is partly due to the high prevalence of associated life-threatening extra-thoracic injuries. However, one principle cause of death consists of pneumonia and sepsis with prolonged intubation. ${ }^{3,13,14}$

Several potential advantages of operative chest wall stabilizations have been reported. These include reduced duration of mechanical ventilation, ${ }^{4,7,8,13,15-17}$ shortened ICU stay and hospitalization, ${ }^{7,8,15}$ and decreased likelihood of clinically significant long-term respiratory dysfunction and skeletal deformity. 5,15

Despite the advantages of operative chest wall fixation, little consensus on the fixation technique exists.

This report describes three cases of flail chest injury managed by operative stabilization with plates and screws. The criteria for surgical intervention in this trauma center are traumatic loss of $30 \%$ of pleural cavity volume, inability to wean an awake patient from the ventilator, inability to control chest wall pain despite epidural catheter, major air leak or major bleeding, or unstable sternal fracture with overlap.

In all three cases a standard posterolateral thoracotomy was performed. The serratus anterior was retracted anteriorly and the latissimus dorsi was divided. To reach more cranially a small portion of the trapezius and the rhomboids were transected in cases 2 and 3 . The chest was always entered and hematoma was removed. Pelvic, mandibular and customized

Submitted for publication November 12, 2002

Accepted for publication February 5, 2003.

Copyright $(2005$ by Lippincott Williams \& Wilkins, Inc.

From the Clinical Research and Technology Center, Legacy Health System, Portland, Oregon.

This study has been supported by a Grant from the Legacy Foundation.

Address for reprints: Michael Bottlang, PhD, Legacy Clinical Research \& Technology Center, 1225 NE 2nd Avenue, Portland, OR 97232; email: mbottlan@1hs.org.

DOI: $10.1097 / 01 . T A .0000063612 .25756 .60$ reconstruction plates were used, with bending stiffness rang-

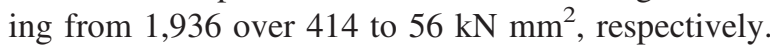

In addition to documentation of the technique, this report describes the results obtained with three distinct osteosynthesis plates and provides a historic overview of alternative fixation means.

\section{CASE 1}

A 34-year-old man was rolled over by a forklift in an industrial accident, sustaining a crush injury to his chest and to his biceps bilaterally. He suffered fractures of ribs 3 to 10, resulting in a right flail chest (Fig. 1) with a mild posterior pulmonary contusion and a hemothorax and a right lobe contusion of the liver. He was admitted to a Level I trauma center with stable vital signs. Approximately 8 hours later he required intubation for hypercarbia.

Three days after admission, open reduction and internal fixation of the flail segment of ribs 6 to 9 was performed. The remaining injured ribs had isolated fractures without instability. Pelvic reconstruction plates were contoured to the chest wall and fixated by 12 to $16 \mathrm{~mm}$ screws (Fig. 2 and 3). These stainless steel plates are $3.5 \mathrm{~mm}$ thick and $10 \mathrm{~mm}$ wide and have a bending stiffness of $1,936 \mathrm{kN} \mathrm{mm}$.

Postoperatively the oxygenation improved and 2 days later the patient could be extubated. He left the ICU on postoperative day 5, and was discharged home 3 days later.

At follow-up examination 2 months after surgery, the patient did not have any shortness of breath but the thoracotomy site was tender to touch. He was able to return to full-time employment 4 months after the injury. The prominent hardware continued to irritate him and was therefore removed half a year later.

\section{CASE 2}

A 49-year-old man was crushed beneath a heavy object and remained trapped for a period of time. He sustained fractures of left ribs 3 to 9 resulting in a flail segment (Fig. 4) with left pulmonary contusion and a left hemopneumothorax. He also suffered from closed head injury, complex pelvic ring injury, left thoracic and lumbar transverse process fractures, and anterior compression fractures of the lumbar vertebrae two and three. He was admitted to a Level I trauma center where ventricular ectopy due to an underlying severe dilated cardiomyopathy and traumatic anemia were also diagnosed. 




Fig. 1. Case 1. Plain anteroposterior radiograph showing the flail segment on the right.

Eight hours after admission deteriorating pulmonary function required intubation.

On the third day after admission the patient underwent pelvic and chest stabilization. Open reduction and internal fixation of ribs 4,5 , and 7 to 9 was performed using mandibular plates with locking head screws (Fig. 5). These 2.4 $\mathrm{mm}$ thick and $8 \mathrm{~mm}$ wide Titanium plates have a bending stiffness of $414 \mathrm{kN} \mathrm{mm}^{2}$ and were contoured to the rib. The fracture in rib 6 was too posterior to be reached. The patient could be weaned from the ventilator on the next day and left the ICU 2 days later. He was discharged home with a back brace 1 week later.

He started on full shift work 6 months after the injury and continually reduced his pain medication over the following few months.

\section{CASE 3}

A 35-year-old woman presented to a Level I trauma center following an all-terrain-vehicle accident with rollover.

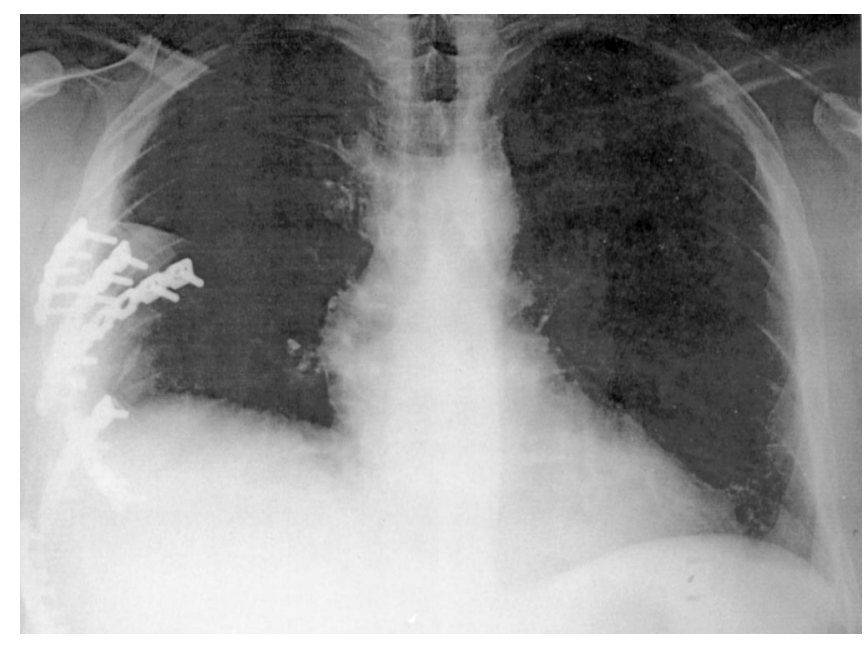

Fig. 2. Case 1. Postoperative anteroposterior radiograph with ribs 6 to 9 reduced and fixated by pelvic reconstruction plates.

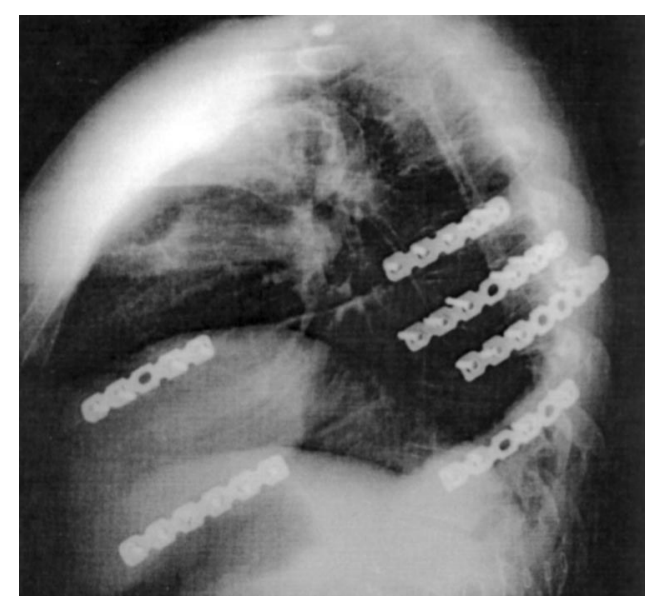

Fig. 3. Case 1. Postoperative lateral radiograph with ribs 6 to 9 reduced and fixated by pelvic reconstruction plates.

On admission, her airway was intact with diminished breathing sounds in the right field. She was diagnosed with a right posterolateral flail chest due to double serial fractures of ribs 3 to 10 (Fig. 6), right lower lobe lung laceration, subcutaneous emphysema from the axilla to the right flank, liver laceration, and a closed midshaft fracture of the right clavicle.

Because respiratory insufficiency and chest deformity increased over the next 6 days, open reduction and internal fixation of the flail chest was performed together with a repair of the clavicle. All ribs were impacted centrally, displaced by several inches. A portion of the third rib was impaled into the lung. After elevation and reduction of the flail segment, ribs 3 to 8 were fixated by customized rib plates. These $1 \mathrm{~mm}$ thick and $10 \mathrm{~mm}$ wide Titanium plates have a bending stiffness of $56 \mathrm{kN} \mathrm{mm}^{2}$. They were contoured, and fixated with $3.0 \mathrm{~mm}$ cortical locking screws (Fig. 7 and 8).

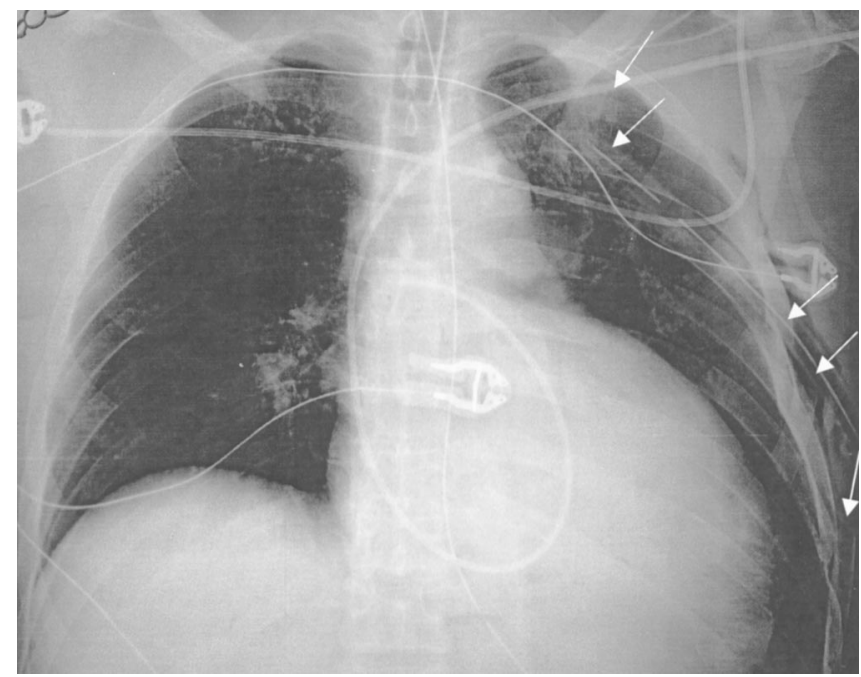

Fig. 4. Case 2. Plain anteroposterior radiograph showing the flail segment on the left. 


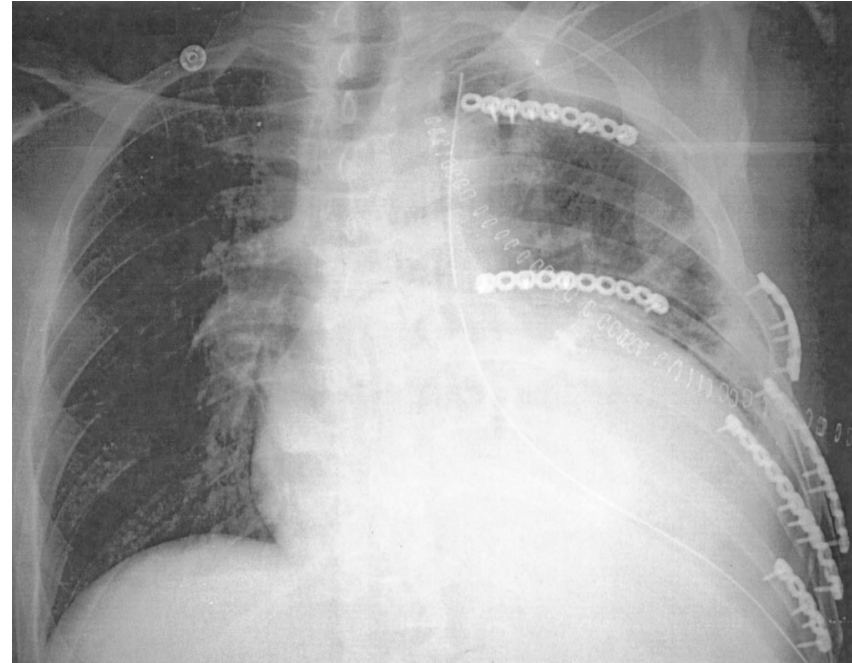

Fig. 5. Case 2. Postoperative anteroposterior radiograph with rib 4 fixated posteriorly; 5, 8, and 9 anteriorly; and rib 7 fixated anteriorly and posteriorly using mandibular reconstruction plates and locking head screws.

On the next day the patient was extubated and transferred to the regular ward without complications. She was discharged home 5 days later.

She returned to full time employment within 14 days. One year later the prominent hardware along the clavicle was removed. However, she did not require removal of the rib plates, did not complain of dyspnea and did not have any tenderness along the thoracotomy.

\section{DISCUSSION}

Rib fractures are common injuries in trauma patients admitted to hospitals. The incidence is reported to be

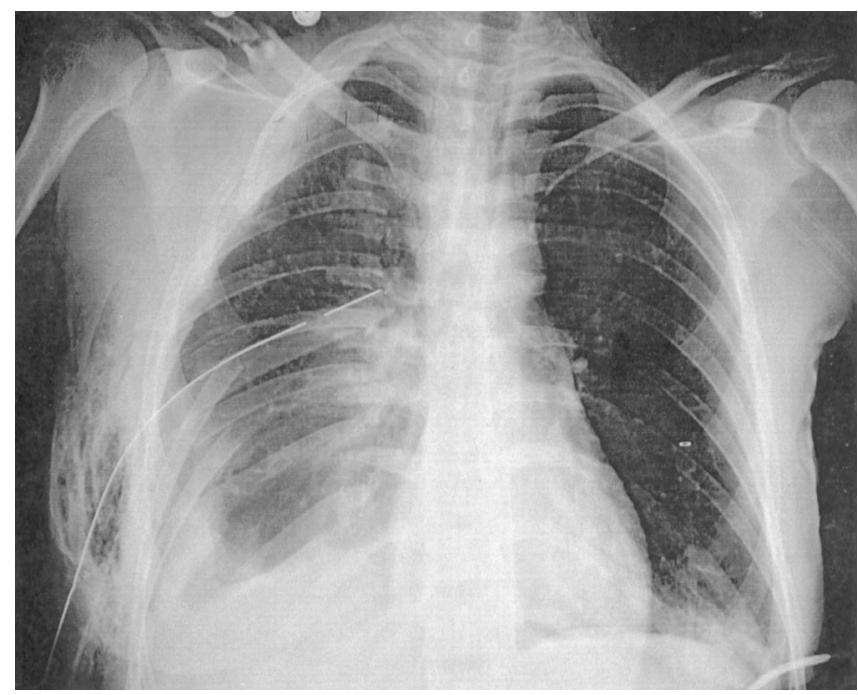

Fig. 6. Case 3. Plain anteroposterior radiograph showing the posterolateral flail segment and the subcutaneous emphysema on the right.

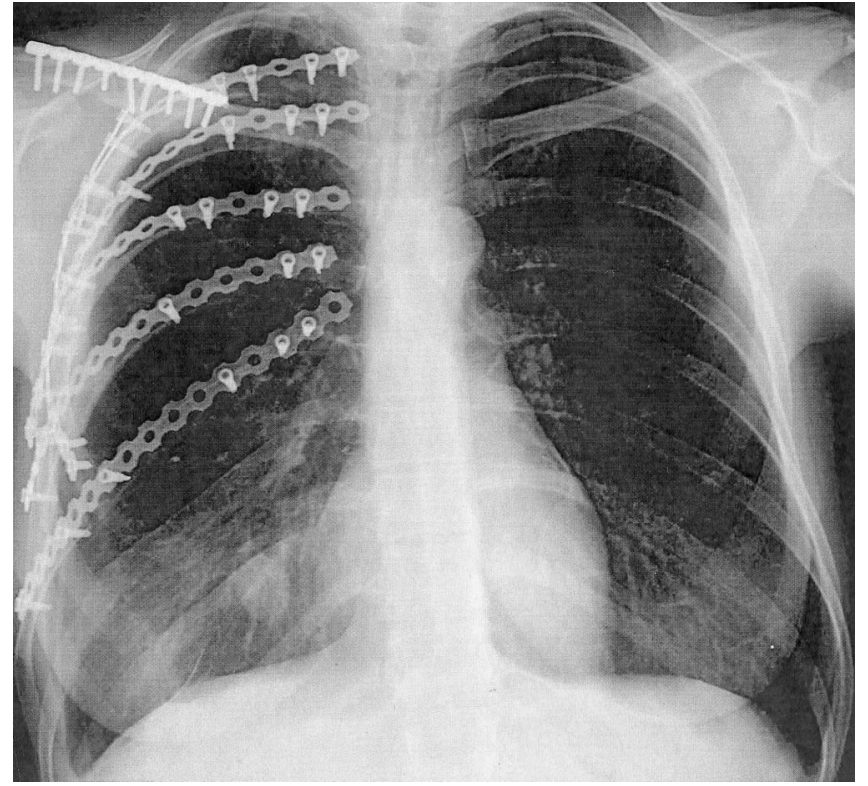

Fig. 7. Case 3. Postoperative anteroposterior radiograph with ribs 3 to 8 reduced and fixated by customized rib plates and locking head screws.

4-10\%. ${ }^{1,18}$ About half of these patients with rib fractures have at least two broken ribs. When four consecutive ribs are fractured, a flail chest is suspected, which is defined as the

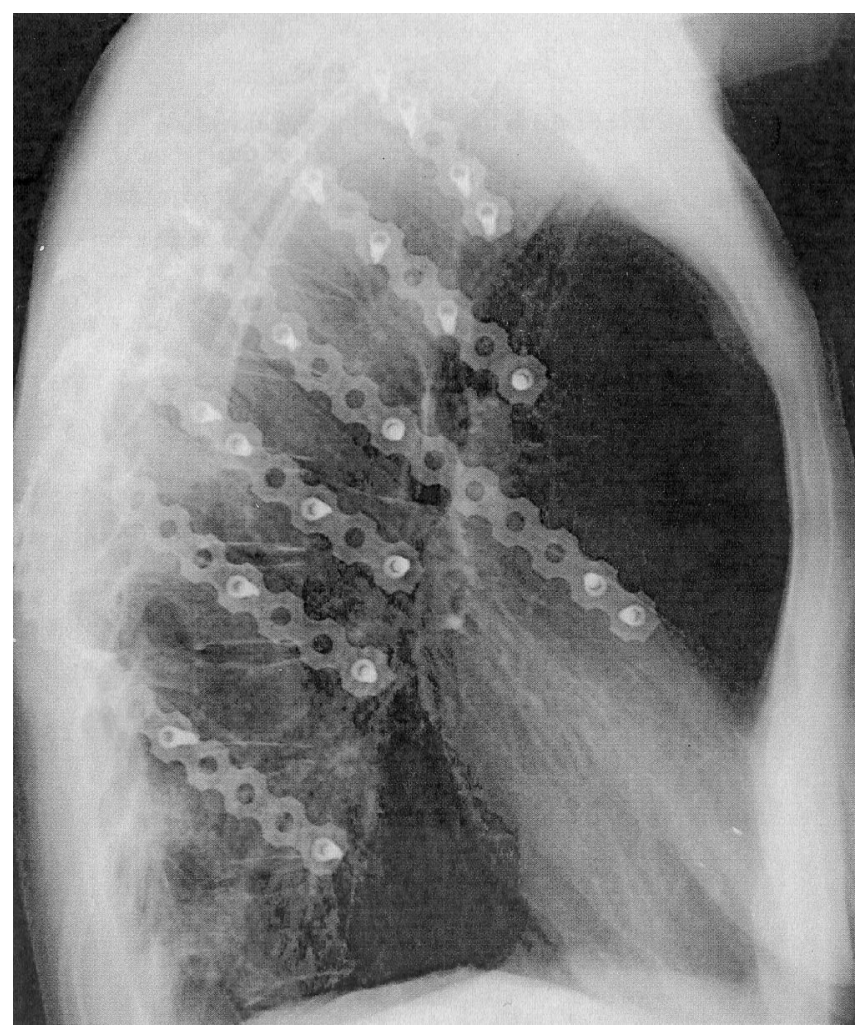

Fig. 8. Case 3. Postoperative lateral radiograph with ribs 3 to 8 reduced and fixated by customized rib plates and locking head screws. 
fracture of at least four consecutive ribs in two or more places. ${ }^{1,3,19}$ Up to $10-15 \%$ of blunt chest trauma injuries will result in a flail chest. ${ }^{2,3,14}$

Fractured ribs in a flail chest treated conservatively may undergo progressive displacement during the healing phase, which results in considerable deformity, volume loss, atelectasis, and chronic pain. ${ }^{7,10,12,19-21}$ Long-term problems of patients with flail chest injuries treated nonoperatively include subjective chest tightness, thoracic cage pain and dyspnea. ${ }^{10,22}$

Indications for surgical stabilization of a flail chest are severe pulmonary restrictions due to the paradoxical movement of the flail segment, ${ }^{2,3,11}$ markedly overriding ribs and severe instability, ${ }^{15,23}$ intra-thoracic lesions which require thoracotomy, ${ }^{2,4,11,14,24-26}$ progressive lung volume loss or deteriorating pulmonary function in non-intubated patients, ${ }^{3,15,27}$ and persistent instability which prevents weaning from the ventilator. ${ }^{3,15,28}$ An extensive pulmonary contusion is considered a relative contraindication by some authors because the patients will require prolonged mechanical ventilation anyway., 36,29 Alternatively, other authors stress the importance to stabilize these patients surgically, so that the patients can ventilate themselves. ${ }^{23,27}$

The ideal indications and the timing for surgical intervention, early or secondary, remains controversial. While pulmonary contusion may indicate secondary stabilization, several recent reports recommend early intervention in selected patients. ${ }^{3,8,16,27,30}$

The problems and risks of an operative approach include the surgical trauma itself and the loosening and migration of implants. ${ }^{2-7,14,24,30-32}$

In all reports reviewed in the literature, patients who underwent surgical stabilization of a flail chest were weaned from the ventilator earlier and left the ICU earlier than the ones treated by intubation and intermittent positive pressure ventilation (3.7-10.8 days vs. 15-30.7 days for mechanical ventilation and $6.8-16.5$ vs. 21-28.3 days of ICU stay). ${ }^{3,5,7,8,16,17,28,31}$ The incidence of chest infection was $7.6-24 \%$ in surgically stabilized patients versus $50-77 \%$ in nonoperated patients. ${ }^{3,7,8}$

A prospective and randomized study of 18 patients who were treated by surgical stabilization versus 19 patients treated with internal pneumatic stabilization showed a shorter ventilation time, shorter ICU stay, and lower incidence of pneumonia in the operative group. ${ }^{8}$ In this study, the percent forced vital capacity was higher at 1 month and thereafter and the percentage of patients returning to full time employment at 6 months was significantly higher in the operative group.

In a long term study (average 5 years, range $0.5-12$ years) of 32 patients with nonoperatively treated flail chest, $25 \%$ complained of subjective chest tightness and $49 \%$ of thoracic cage pain; $43 \%$ returned to full time employment. Spirometry was abnormal in 57\%. 50\% revealed mild, and $20 \%$ moderate, objective dyspnea. ${ }^{10}$
This decrease in air volume may result from a combination of thoracic deformity and fibrous changes due to pulmonary contusion. In CT measurements 1-6 years after trauma the hemithoracic space was significantly smaller on the former flail side. ${ }^{21}$

After surgical stabilization of flail chest injury, 95-100\% returned to full preoperative work capacity. ${ }^{3,28}$ In a different study, $11 \%$ of patients with surgical stabilization complained of persistent postoperative pain after 6 months (compared with $49 \%$ of patients with persistent thoracic cage pain without operation reported by Landercasper et al., ${ }^{10}$ half of which improved after plate removal ${ }^{3}$ ).

Four categories of fixation devices for operative chest wall fixation have been described in the literature; plates, intramedullary devices, vertical bridging, and wiring.

1. Plates. Most general osteosynthesis plates exceed by far the bending stiffness of ribs. Therefore loosening of the outermost screws has been reported, especially in osteoporotic ribs. $^{2-4,6,14,32,33}$ The special rib plates on the other hand (Judet-, Vecsei-, Labitzke-, Rehm-plate) have a very low stiffness and therefore can lead to unstable healing conditions. ${ }^{33}$

It is difficult to reach the more posterior fractures with these plates. ${ }^{18,29}$ In the ventral and the costochondral rib segment, reliable screw fixation is difficult at best. ${ }^{29}$

General as well as special rib plates all require contouring to match the rib geometry. ${ }^{34-37}$

2. Intramedullary devices require smaller incisions. Kirschner wires are mainly used for intramedullary fixation. However, their circular cross-section provides little rotational stability and lack of secure fixation inside the canal can lead to wire migration. ${ }^{5,7,23,29,36}$

To prevent migration intramedullary rib struts were introduced. ${ }^{20}$ The Rehbein plate is a thin intramedullary plate with a bent end that can be fixed to the outer cortex. However, implanting the device can lead to additional fractures of the cortex, especially in osteoporotic bone. ${ }^{5}$

For anterolateral fractures close to the cartilage, some authors describe combinations of intramedullary devices with plates. ${ }^{13,38}$

3. Vertical bridging. There are different implants described that may bridge the flail segment such as palacos prosthesis, ${ }^{39}$ Kirschner wires, ${ }^{40,41}$ rib struts, ${ }^{42}$ and rib grafts. ${ }^{43,44}$ The advantage of this method is the ease of implant insertion and removal. However, the technique does not accommodate the physiologic respiratory movement of the rib cage, especially the intercostal space widening during inspiration, which starts for individual ribs at different times during inspiration (5th rib first) and varies between $-3 \mathrm{~mm}$ (I/II rib) and $+7 \mathrm{~mm}(\mathrm{~V} / \mathrm{VI}){ }^{45}$

4. Wiring. A variety of wiring or suturing techniques ${ }^{29,44}$ have been reported. However, these techniques generally do not provide a sufficient stability of the fracture, and non-union may occur. ${ }^{29,33}$ 
In this case report three plate designs (Fig. 9) with highly different structural properties were used. Flexural rigidity between the implants varied greatly, and was therefore quantified by standard four-point bending tests. The implants yielded flexural rigidity values of $1,936 \mathrm{kN} \mathrm{mm}^{2}, 414$, and 56 $\mathrm{kN} \mathrm{mm}{ }^{2}$ for the pelvic, the mandibular, and the customized reconstruction plate, respectively. For comparison, two human cadaveric ribs were tested at seven different sites, resulting in a flexural rigidity of $1,043 \pm 645 \mathrm{kN} \mathrm{mm}^{2}$.

Due to its high flexural rigidity the pelvic reconstruction plate provided a stable fracture fixation. However, the prominent hardware caused postoperative chest wall pain requiring removal. Furthermore, there is anecdotal evidence of screw loosening with these plates. The mandibular-and the customized reconstruction plate can both be used with locking head screws. Therefore, the healing process does not rely on exact contouring of the plate and the periosteum remains almost intact. The mandibular reconstruction plate is more prominent when used with locking head screws but it did not require removal in case 2 . Despite the very thin soft tissue coverage in a thin patient, as in case 3 , the low profile customized plate did not lead to tenderness or pain and could remain in place. However, as shown above, its flexural rigidity is lower than the flexural rigidity of human ribs.

A common limitation to any plate design is the difficulty of stabilizing posterior fractures.

In conclusion, operative fixation of flail chest segments has been successfully achieved with a variety of osteosynthesis plates. Due to the general lack of commercially available plates for rib fracture fixation, alternative plates with widely variable constitutive properties have been used. Future research is necessary to design a specific rib plate which takes into account the structural properties and fixation constraints of ribs, to simplify the fixation technique, and to reduce complications.

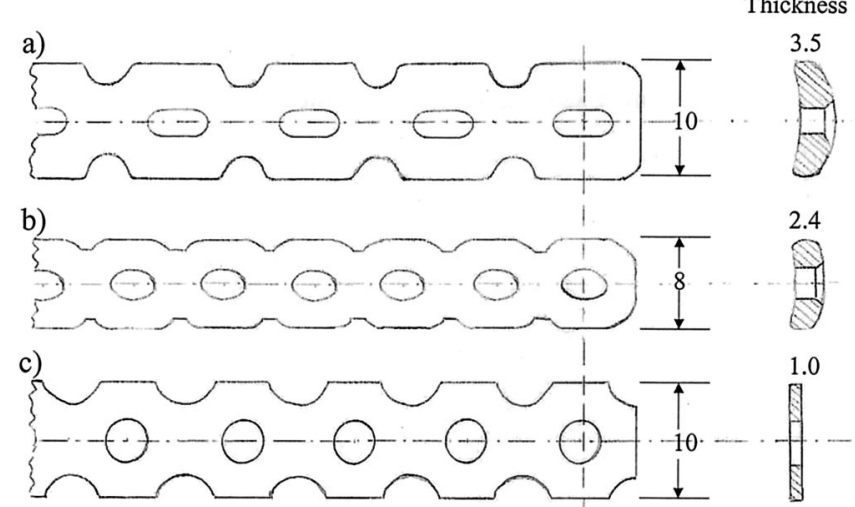

Fig. 9. Technical drawing of the three different plates used: (A) pelvic reconstruction plate, $(\boldsymbol{B})$ mandibular reconstruction plate, (C) customized plate

\section{ACKNOWLEDGMENTS}

We thank Marcus Mohr and Eduard Abrams from the Legacy Biomechanics Laboratory for their great help on the four-point bending tests.

\section{REFERENCES}

1. Mayberry J, Trunkey D. The fractured rib in chest wall trauma. Chest Surg Clin North Am. 1997;7:239-261.

2. Hellberg K, de Vivie E, Fuchs K, et al. Stabilization of flail chest by compression osteosynthesis-experimental and clinical results. Thorac Cardiovasc Surgeon. 1981;29:275-281.

3. Lardinois D, Krueger T, Dusmet M, Ghisleta N, Gugger M, Ris H. Pulmonary function testing after operative stabilisation of the chest wall for flail chest. Eur J Cardiothorac Surg. 2001;20:496-501.

4. Labitzke R, Schmit-Neuerburg K, Schramm G. Indikation zur Thoracotomie und Rippenstabilisierung beim Thoraxtrauma im hohen Lebensalter. Chirurg. 1980;51:576-580.

5. Meier P, Schuepbach P. Zur Therapie des instabilen Thorax. Schweiz, Med Wschr. 1978;108:608-613.

6. Friedrich B, Redeker H, Kljucar S. Die instabile Thoraxwand:Behandlungsmoeglichkeiten. Helv Chir Acta. 1991; 58:77-82.

7. Ahmed Z, Mohyuddin Z. Management of flail chest injury: internal fixation versus endotracheal intubation and ventilation. $J$ Thorac Cardiovasc Surg. 1995;110:1676-80.

8. Tanaka H, Yukioka T, Yamaguti Y, et al. Surgical stabilization or internal pneumatic stabilization? A prospective randomized study of management of severe flail chest patients. J Trauma. 2002;52:727732.

9. Thomas A, Blaisdell W, Lewis F, Schlobohm R. Operative stabilization for flail chest after blunt trauma. $J$ Thorac Cardiovasc Surg. 1978;75:793-99.

10. Landercasper J, Cogbill T, Lindesmith L. Long-term disability after flail chest injury. $J$ Trauma. 1984;24:410-414.

11. Schmit-Neuerburg H, Weiss H, Labitzke R. Indication for thoracotomy and chest wall stabilization. Injury. 1982;14:26-34.

12. Cacchione R, Richardson D, Seligson D. Painful nonunion of multiple rib fractures managed by operative stabilization. J Trauma. 2000;48:319-321.

13. Tscharner C, Schuepbach P, Meier P, Nachbur B. Zur operativen Behandlung des instabilen Thorax bei respiratorischer Insuffizienz. Helv Chir Acta. 1988;55:711-717.

14. Labitzke R. Die Bedeutung der Thorakotomie und Brustwandstabilisierung mit Rippenklammern im Behandlungskonzept des Thoraxtraumas. Zbl Chirurgie. 1981; 106:1351-1359.

15. Haasler GB. Open fixation of flail chest after blunt trauma. Ann Thorac Surg. 1990;49:993-995.

16. Voggenreiter G, Neudeck F, Aufmkolk M, Obertacke U, Schmit N. Behandlungergebnisse der operativen Thoraxwandstabilisierung bei instabilem Thorax mit und ohne Lungenkontusion. Unfallchirurg. 1996;99:425-434.

17. Voggenreiter G, Neudeck F, Aufmkolk M, Obertacke U, SchmitNeuerburg K. Operative chest wall stabilization in flail chestoutcomes of patients with or without pulmonary contusion. $J \mathrm{Am}$ Coll Surg. 1998;187:130-138.

18. Kessler E. Neue Gesichtspunkte bei der operativen Versorgung des Thoraxwandbruches. Thoraxchirurgie. 1978;26:280-285.

19. Slater M, Mayberry J, Trunkey D. Operative stabilization of flail chest six years after injury. Ann Thorac Surg. 2001;72:600-601.

20. Paris F, Tarazona V, Blasco E, et al. Surgical stabilization of traumatic flail chest. Thorax. 1975;30:521-527.

21. Kishikawa M, Minami T, Shimazu T, et al. Laterality of air volume in the lungs long after blunt chest trauma. J Trauma. 1993;34:908913. 
22. Beal S, Oreskovich M. Long term disability associated with flail chest injury. Am J Surg. 1985;150:324-326.

23. Moore B. Operative stabilization of nonpenetrating chest injuries. J Thorac Cardiovasc Surg. 1975;70:619-630.

24. Sanchez-Lloret J, Letang E, Mateu M, Callejas M, Catalan M, Mestres C. Indications and surgical technique of the traumatic flail chest syndrome. Thorac Cardiovasc Surgeon. 1982;30:294-297.

25. Lindenmaier H, Kuner E, Walz H. Die operative Behandlung der Thoraxwandinstabilitaet. Unfallchirurg. 1990;16:172-177.

26. Actis Dato G, Aidala E, Ruffini E. Surgical management of flail chest. Ann Thorac Surg. 1999;67:1826-1827.

27. Karev D. Operative Management of the flail chest. Wiadomosci Lekarskie. 1997;50:205-208.

28. Mouton W, Lardinois D, Furrer M, Regli B, Ris H. Long-term follow-up of patients with operative stabilization of a flail chest. Thorac Cardiovasc Surgeon. 1997;45:242-244.

29. Albrecht F, Brug E. Die Zuggurtungsosteosynthese der Rippen und des Sternums bei instabiler Thoraxwand. Zbl Chirurgie. 1979; 104:770-776.

30. Reber P, Ris H, Inderbitzi R, Stark B, Nachbur B. Osteosynthesis of the injured chest wall. Scand J Thor Cardiovasc Surg. 1993;27:137142.

31. Labitzke R. Biomechanic examination of rib plates. Langenbecks Arch Chir. 1981;354:169-171.

32. Boetsch H, Rehm K. Biomechanische Untersuchungen an Rippenosteosynthesen. Biomed Technik. 1981;26:296-301.

33. Martin P, Godinou J, Monod R, et al. Costal stapling in severe thoracic traumas. Nouv Presse Med. 1982;11:851-854.

34. Borrely J, Grosdidier G, Wack B. Surgical treatment of flail chest by sliding staples. Rev Chir Orthop Reparatrice Appar Mot. 1985; 71:241-250.
35. Menard A, Testart J, Philippe J, Grise P. Treatment of flail chest with Judets struts. J Thorac Cardiovasc Surg. 1983;86:300-305.

36. Vecsei V, Frenzel I, Plenk H Jr. Eine neue Rippenplatte zur Stabilisierung mehrfacher Rippenbrueche und der Thoraxwandfraktur mit paradoxer Atmung. Hefte Unfallheilkd. 1979;138:279-282.

37. Di Fabio D, Benetti D, Benvenuti M, Mombelloni G. Surgical stabilization of post-traumatic flail chest. Our experience with 116 cases treated. Minerva Chir. 1995;50:227-233.

38. Glavas M, Altarac S, D V, Ivancic A, Drazinic I. Flail chest stabilization with palacos prosthesis. Acta Medica Croatica, 2001. 2001;55:91-95.

39. Guernelli N, Bragaglia R, Briccoli A, Mastrorilli M, Vecchi R. Technique for the management of anterior flail chest. Thorax. 1979; 34:247-248.

40. Beltrami V, Martinelli G, Giansante P, Gentile K. An original technique for surgical stabilization of traumatic flail chest. Thorax. 1978;33:528-529.

41. Volkmer I, Krespis E, Stapenhorst K. Der instabile Thorax, ein Beitrag zur operativen Behandlung. Thoraxchirurgie. 1978;26:275279.

42. Sherman J, Salzberg A, Raskin N, Beattie E. Chest wall stabilization using plate fixation. Ann Thorac Surg. 1988;46:467-469.

43. Graeber G, Cohen D, Patrick D, Wolf R, Hotard M, Zajtchuk R. Rib fracture healing in experimental flail chest. J Trauma. 1985;25:903908.

44. Fick R, Bartels P, Brunn A, Disse J. Handbuch der Anatomie des Menschen. Anatomie und Mechanik der Gelenke unter Berücksichtigung der bewegenden Muskeln, ed. Fick R. Vol. 2,1,3. 1911, Jena: Verlag von Gustav Fischer. 688.

45. Shah T. Internal fixation for flail chest [Letter]. $J$ Thorac Cardiovasc Surg. 1996;112:849-850. 